\title{
Differential expression and regulation of cylooxygenases, prostaglandin E synthases and prostacyclin synthase in rat uterus during the peri-implantation period
}

\author{
Jing Cong, Hong-Lu Diao, Yue-Chao Zhao, Hua Ni, Yun-Qin Yan and Zeng-Ming Yang \\ College of Life Sciences, Northeast Agricultural University, Harbin 150030, People's Republic of China \\ Correspondence should be addressed to Z-M Yang; Email: zmyang@mail.neau.edu.cn
}

\begin{abstract}
It has been shown that both prostaglandin 2 (PGI2) and PGE2 are essential for mouse implantation, whereas only PGE2 is required for hamster implantation. To date, the expression and regulation of cyclooxygenase (COX) and prostaglandin $\mathrm{E}$ synthase (PGES), which are responsible for PGE2 production, have not been reported in the rat. The aim of this study was to examine the expression pattern and regulation of COX-1, COX-2, membrane-associated PGES-1 (mPGES-1), mPGES-2 and cytosolic PGES (CPGES) in rat uterus during early pregnancy and pseudopregnancy, and under delayed implantation. At implantation site on day 6 of pregnancy, COX-1 immunostaining was highly visible in the luminal epithelium, and COX-2 immunostaining was clearly observed in the subluminal stroma. Both mPGES-1 mRNA and protein were only observed in the subluminal stroma surrounding the implanting blastocyst at the implantation site on day 6 of pregancy, but were not seen in the inter-implantation site on day 6 of pregnancy and on day 6 of pseudopregnancy. Our data suggest that the presence of an active blastocyst is required for mPGES-1 expression at the implantation site. When pregnant rats on day 5 were treated with nimesulide for $24 \mathrm{~h}$, mPGES-1 protein expression was completely inhibited. cPGES immunostaining was clearly observed in the luminal epithelium and subluminal stromal cells immediately surrounding the implanting blastocyst on day 6 of pregnancy. mPGES-2 immunostaining was clearly seen in the luminal epithelium at the implantation site. Additionally, immunostaining for prostaglandin I synthase (PGIS) was also strongly detected at the implantation site. In conclusion, our results indicate that PGE2 and PGI2 should have a very important role in rat implantation.
\end{abstract}

Reproduction (2006) 131 139-151

\section{Introduction}

One of the first detectable signs of implantation is an increase in endometrial vascular permeability at the sites of blastocyst apposition and the initiation of the decidual cell reaction (Psychoyos 1986). It has been shown that prostaglandin E2 (PGE2) is able to restore the endometrial vascular permeability response and decidualization (Kennedy \& Lukash 1982, Keys \& Kennedy 1990, Hamilton \& Kennedy 1994). Additionally, PGE2 plays a major role in the hatching of mouse blastocysts (Baskar et al. 1981), is able to induce implantation of mouse blastocysts (Holmes \& Gordashko 1980) and may also have immunomodulatory roles at the implantation site (Lala 1989).

Cyclooxygenase (COX) exists in two isoforms, COX-1 and COX-2, and can catalyze the bis-oxygenation of arachidonic acid leading to the production of PGG2 and the reduction of 15-hydroperoxide of PGG2 to form $\mathrm{PGH} 2$ (Smith et al. 2000). COX-1 appears to be constitutively synthesized in many tissues (Seibert et al. 1994, Samet et al. 1995). However, COX-2 expression is up-regulated in response to various pro-inflammatory or mitogenic agents (Hla \& Neilson 1992, Smith et al. 1994). In mouse uterus during early pregnancy, COX-1 is present before implantation in the luminal epithelium and subepithelial stromal cells, whearas COX-2 is locally expressed in the uterus in the region surrounding the implanting blastocyst at the time of embryo attachment and persists until early on day 5 (Chakraborty et al. 1996). In gene knockout studies with COXs, COX-1-deficient female mice are fertile with specific parturition defects, whereas COX-2deficient females are infertile with abnormalities in ovulation, fertilization, implantation and decidualization (Dinchuk et al. 1995, Langenbach et al. 1995, Lim et al. 1997). Recently, Wang et al. (2004a) reported that the reproductive abnormalities in COX-2-deficient mice depend upon genetic background.

PGE2 can bind to and activate a set of functionally distinct cell surface receptors - EP1, EP2, EP3 
and EP4 - which are classified on the basis of their responses to various agonists and antagonists to PGE2 (Negishi et al. 1995). PGE synthase (PGES) is a terminal prostanoid synthase and can enzymatically convert the cyclooxygenase product $\mathrm{PGH} 2$ to PGE2. There are four isoforms of PGES: membrane-associated PGES (mPGES)-1, mPGES-2, cytosolic PGES (cPGES) and glutathione S-transferase (GST) $\mu$ (Murakami \& Kudo 2004). mPGES-1, a membrane-associated and inducible perinuclear enzyme with glutathione-dependent activity, is expressed in a variety of tissues including prostate, testis and small intestine (Jakobsson et al. 1999). mPGES-1 is preferentially coupled with the inducible COX-2 to promote delayed PGE2 generation and, if COX-2 already exists in cells, can also regulate immediate PGE2 generation (Murakami et al. 2000). mPGES-2, constitutively expressed in various cells and tissues, can be coupled with both COX-1 and COX-2, and may play a role in the production of the PGE2 involved in both tissue homeostasis and disease (Murakami et al. 2003). cPGES is constitutively expressed in a wide variety of cells and tissues, and is predominantly linked with COX-1 to promote the immediate response, during which a relatively high concentration of arachidonic acid is released in a short period (Tanioka et al. 2000).

mPGES-1 mRNA and protein were highly expressed in the stroma immediately surrounding the blastocyst but not in the luminal epithelium in mouse uterus on day 5 of pregnancy. There was no mPGES-1 expression on day 5 of pseudopregnancy and under delayed implantation, suggesting that mPGES-1 expression at the implantation site requires the presence of an active blastocyst ( $\mathrm{Ni}$ et al. 2002). mPGES-1 is also highly expressed at implantation sites in hamster uterus (Wang et al. 2004b). In mouse uterus, CPGES expression is at a high level at implantation sites and in the decidual cells ( $\mathrm{Ni}$ et al. 2003). However, the expression pattern of mPGES-2 in the rodent uterus has yet to be examined.

Among various prostaglandins, PGE2 and prostacyclin (PGI2) have been considered as the primary candidates involved in implantation and decidualization in the mouse (Lim et al. 1999, Ni et al. 2002). In contrast, in the rat, PGE2 but not PGI2 is a key mediator of increased vascular permeability at the implantation site (Kennedy 1979). PGE2 also plays a key role during hamster implantation (Wang et al. 2004b). To date, the expression and regulation of COX and PGES in rat uterus during early pregnancy have not been reported. The aim of this study was to examine the expression pattern and regulation of COX-1, COX-2, mPGES-1, mPGES-2, cPGES and prostacyclin synthase (PGIS) in rat uterus during early pregnancy.

\section{Materials and Methods}

\section{Animals and treatments}

Mature rats (Sprague-Dawley strain) were caged in a controlled environment (14 $\mathrm{h}$ light:10 $\mathrm{h}$ darkness). All animal procedures were approved by the Institutional Animal Care and Use Committee of Northeast Agricultural University. Adult females were mated with fertile males of the same strain to induce pregnancy (day $1=$ the day of vaginal plug). Pregnancy on days $1-5$ was confirmed by recovering embryos from the reproductive tracts. The implantation sites on day 6 were identified by i.v. injection of $1 \mathrm{ml}$ of $1 \%$ Chicago blue (Sigma) in $0.85 \%$ sodium chloride. At least three rats were used in each stage or treatment in this study.

Pseudopregnancy was induced by caging adult females with vasectomized males and was confirmed by checking the vaginal plug (either in the vagina or on the cage floor) the next morning. The uteri were collected on days 1, 5 and 6 of pseudopregnancy respectively.

To induce delayed implantation, the pregnant rats on day 4 of pregnancy were treated with progesterone $(5 \mathrm{mg} / \mathrm{rat}$, s.c.; Sigma) and then ovariectomized at 0830-0900 h. Progesterone $(5 \mathrm{mg} / \mathrm{rat})$ was injected to maintain delayed implantation from days 5-7. The progesterone-primed delayed-implantation rats were treated with estradiol-17 $\beta$ ( $250 \mathrm{ng} / \mathrm{rat}$; Sigma) to terminate delayed implantation. The rats were killed by stunning and cervical dislocation to collect uteri at 24 and $36 \mathrm{~h}$ after estrogen treatment. The implantation sites were also identified by i.v. injection of Chicago blue solution. Delayed implantation was confirmed by flushing the blastocysts from the uterus.

\section{Treatments with inhibitors}

In order to examine the effects of nimesulide (a COX-2specific inhibitor) on implantation, pregnant rats were treated with nimesulide $(40 \mathrm{mg} / \mathrm{kg}$ in $0.2 \mathrm{ml}$ DMSO; Cayman Chemical, Ann Arbor, MI, USA) on day 5 for $24 \mathrm{~h}$ or treated twice on both days 5 and 6 for $48 \mathrm{~h}$. The rats were killed to collect uteri at 24 and $48 \mathrm{~h}$ respectively.

\section{Immunohistochemistry}

Rat uteri were immediately fixed in Bouin's solution for $24 \mathrm{~h}$, dehydrated and embedded in paraffin wax. Sections $(7 \mu \mathrm{m})$ were cut, deparaffinized and rehydrated. Nonspecific binding was blocked in $10 \%(\mathrm{v} / \mathrm{v})$ normal horse serum in PBS at $37^{\circ} \mathrm{C}$ for $1 \mathrm{~h}$. The sections were incubated with rabbit anti-human $\mathrm{mPGES}-1$, rabbit anti-human CPGES, rabbit anti-human mPGES-2, rabbit anti-human COX-2, rabbit anti-mouse PGIS (Cayman Chemical) or goat anti-human COX-1 (Santa Cruz Biotechnology, Inc., CA, USA) in $10 \%(\mathrm{v} / \mathrm{v})$ horse serum at $4{ }^{\circ} \mathrm{C}$ overnight. The sections were then incubated with biotinylated goat antirabbit IgG or biotinylated rabbit anti-goat IgG followed by a streptavidin-alkaline phosphatase complex and Vector Red according to the manufacturer's protocol (Vectastain ABC-AP kit; Vector Laboratories, Burlingame, CA, USA). Vector Red was visualized as a red color. Endogenous alkaline phosphatase activity was inhibited by supplementing $1 \mathrm{mM}$ levamisole (Sigma) into the Vector Red substrate solution. Moreover, the same concentration of 
normal rabbit $\lg \mathrm{G}$ or goat $\lg \mathrm{G}$ was used in place of the corresponding primary antibody as a negative control. For rabbit anti-mPGES-1 antibody, a specific blocking peptide (Cayman Chemical) was preincubated with the primary antibody for $30 \mathrm{~min}$ and then incubated with sections. The sections were counter-stained with hematoxylin and mounted. The degree of immunostaining was assessed subjectively by blinded examination of the slides by two investigators.

\section{In situ hybridization}

A $427 \mathrm{bp}$ (108-518bp) mPGES-1 cDNA fragment was reverse transcribed and amplified with forward primer $5^{\prime}$ CGGAATTCACACTGCTGGTCATCAAG and reverse primer 5'-CGGGATCCTTCAGCTGCTGGTCACAG (Genbank accession number AB041997) with the total RNA from mouse uterus. In these primers, protection bases (CG) and an EcoRI site were added at the $5^{\prime}$ end of the forward primer, and protection bases (CG) and a BamH1 site at the $5^{\prime}$ end of the reverse primer. The PCR fragment for mPGES-1 was recovered from the agarose gel and cloned into pGEM-3Zf $(+)$ plasmid through EcoRI and BamH1 sites respectively. The cloned mPGES-1 fragment was further verified by sequencing. These plasmids were linearized with appropriate enzymes for labeling. Digoxigenin (DIG)labeled antisense or sense cRNA probes were transcribed in vitro using a DIG RNA labeling kit (T7 for sense, SP6 for antisense; Roche).

Uteri were cut into $4-6 \mathrm{~mm}$ pieces and flash frozen in liquid nitrogen. Frozen sections $(10 \mu \mathrm{m})$ were mounted on 3-aminopropyltriethoxy-silane (Sigma)-coated slides and fixed in $4 \%$ paraformaldehyde solution in PBS. The sections were washed in PBS twice, treated in $1 \%(\mathrm{v} / \mathrm{v})$ Triton-100/PBS for $20 \mathrm{~min}$ and again washed three times in PBS. Following prehybridization washes in $50 \%(\mathrm{v} / \mathrm{v})$ formamide and $5 \times$ SSC $(1 \times$ SSC is $0.15 \mathrm{M}$ sodium chloride, $0.015 \mathrm{M}$ sodium citrate) at room temperature for $15 \mathrm{~min}$, the sections were hybridized in the hybridization buffer $(5 \times \mathrm{SSC}, \quad 50 \% \quad(\mathrm{v} / \mathrm{v})$ formamide, $0.02 \% \quad(\mathrm{w} / \mathrm{v}) \quad \mathrm{BSA}$, $250 \mu \mathrm{g} / \mathrm{ml}$ yeast tRNA, $10 \%$ (w/v) dextran sulfate, $1 \mu \mathrm{g} / \mathrm{ml}$ denatured DIG-labeled antisense or sense RNA probe for mouse mPGES-1) at $55^{\circ} \mathrm{C}$ for $16 \mathrm{~h}$. After hybridization, the sections were washed for stringency in $50 \%$ $(\mathrm{v} / \mathrm{v})$ formamide $/ 5 \times \mathrm{SSC}$ at $55^{\circ} \mathrm{C}$ for $15 \mathrm{~min}, 50 \%(\mathrm{v} / \mathrm{v})$ formamide $/ 2 \times \mathrm{SSC}$ at $55^{\circ} \mathrm{C}$ for $30 \mathrm{~min}, 50 \%(\mathrm{v} / \mathrm{v})$ formamide/ $0.2 \times \mathrm{SSC}$ at $55^{\circ} \mathrm{C}$ twice for $30 \mathrm{~min}$ each and $0.2 \times \mathrm{SSC}$ at room temperature for $5 \mathrm{~min}$. After nonspecific binding was blocked in $1 \%(\mathrm{w} / \mathrm{v})$ block mix (Roche) for $1 \mathrm{~h}$, the sections were incubated in sheep antiDIG antibody conjugated to alkaline phosphatase (1:5000; Roche) in 1\% block mix (Roche) overnight at $4{ }^{\circ} \mathrm{C}$. The signal was visualized with $0.4 \mathrm{mM} 5$-bromo-4chloro-3-indolyl phosphate and $0.4 \mathrm{mM}$ nitroblue tetrazolium in the buffer containing $100 \mathrm{mM}$ Tris- $\mathrm{HCl}, \mathrm{pH}$ 9.5, $100 \mathrm{mM} \mathrm{NaCl}$ and $50 \mathrm{mM} \mathrm{MgCl}_{2}$. Endogenous alkaline phosphatase activity was inhibited with $2 \mathrm{mM}$ levamisole
(Sigma). Sections were counter-stained with $1 \%(\mathrm{w} / \mathrm{v})$ methyl green in $0.12 \mathrm{M}$ glacial acetic acid and $0.08 \mathrm{M}$ sodium acetate for $30 \mathrm{~min}$.

\section{Results \\ COX-1 immunostaining during early pregnancy}

COX-1 immunostaining in the rat uterus during early pregnancy is shown in Fig. 1. There was a low level of COX-1 immunostaining in the luminal epithelium on days 1-3 of pregnancy (Fig. 1A). On days 4 and 5, COX-1 immunostaining reached a high level in the luminal epithelium (Fig. 1B). On day 6, COX-1 immunostaining was highly visible in the luminal epithelium and at a basal level in the subluminal stroma at the implantation site (Fig. 1C), whereas a slightly lower level of COX-1 immunostaining was detected in the luminal epithelium at the interimplantation site (Fig. 1D). On day 7, a low level of COX-1 immunostaining was seen in the luminal epithelium and primary decidua (Fig. 1E). On days 8 and 9, a low level of COX-1 immunostaining was observed in the whole decidua (Fig. 1F).

During pseudopregnancy, COX-1 immunostaining was not seen in the uterus on day 1 . However, a high level of COX-1 immunostaining was observed in the luminal epithelium on days 5 and 6 of pseudopregnancy (Fig. 1G and $\mathrm{H})$.

\section{COX-2 immunostaining in the rat uterus during early pregnancy}

COX-2 immunostaining in the rat uterus during early pregnancy is shown in Fig. 2. There was no detectable COX-2 immunostaining in the uteri on days 1 and 2 of pregnancy (data not shown). On days 3 and 4, a low level of COX-2 immunostaining was located in the scattered population of subluminal stromal cells (Fig. 2A and B). In the morning of day 5, COX-2 immunostaining was strongly localized in the stromal cells underlying the luminal epithelium (Fig. 2C). At $2400 \mathrm{~h}$ on day 5 when the attachment reaction began, COX-2 immunostaining was also strongly detected in the subluminal stroma (Fig. 2D). At the implantation site on day 6, COX-2 immunostaining was detected in the stromal cells, but not in the primary decidual zone at the anti-mesometrial side (Fig. 2E). However, COX-2 immunostaining was strongly detected in the whole stromal cells near the lumen at the anti-mesometrial side at the inter-implantation site on day 6 (Fig. $2 \mathrm{~F})$. On day 7, COX-2 immunostaining was detected in both the secondary decidual zone and a layer of decidual cells underlying the luminal epithelium, but not in the rest of the primary decidual zone (Fig. 2G). On days 8 and 9, COX-2 immunostaining was weak in the stromal cells on the mesometrium side and highly visible in the connective tissues between the longitudinal and circular muscles, but not in the decidua (Fig. $2 \mathrm{H}$ ). 

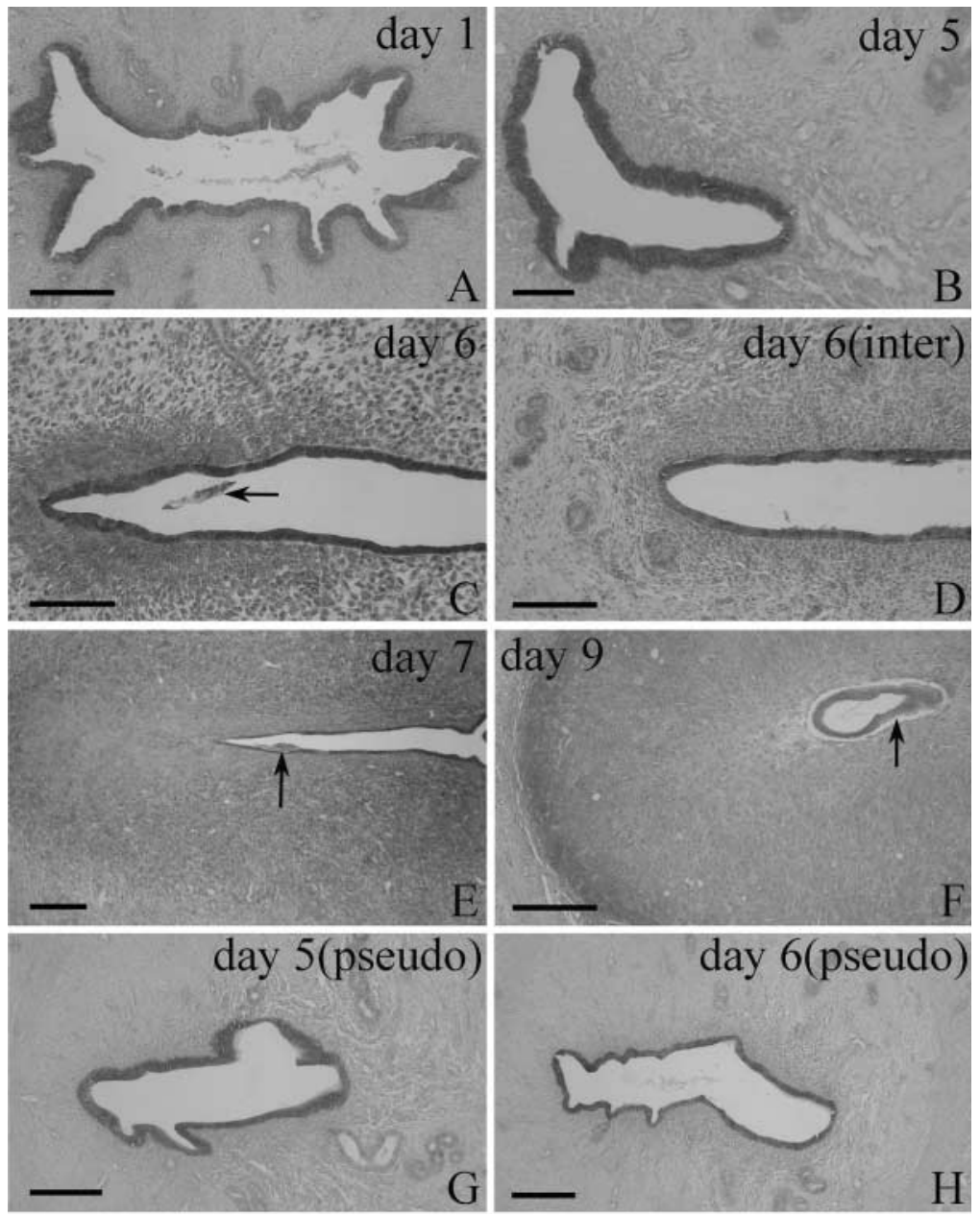

Figure 1 COX-1 immunostaining in rat uteri during early pregnancy on days 1 (A), 5 (B), 6 (C, implantation site), 6 (D, inter-implantation site), 7 (E) and 9 (F). COX1 immunostaining was also observed in the luminal epithelium in rat uteri on days $5(\mathrm{G})$ and $6(\mathrm{H})$ during pseudopregnancy. Abbreviations: de, deciduas; g, gland; le, luminal epithelium; lu, lumen; st, stroma. Arrows indicate embryos; scale bar, $60 \mu \mathrm{m}$.
On day 5 of pseudopregnancy, COX-2 immunostaining was detected in the subluminal stroma at the anti-mesometrial side (Fig. 2l). However, no immunostaining was seen in the uterus on day 6 of pseudopregnancy (Fig. 2J).

\section{mPGES-1 mRNA expression during early pregnancy}

In situ hybridization of mPGES-1 mRNA is shown in Fig. 3. On days 1-5, there were no detectable mPGES-1 mRNA signals in the whole uteri (Fig. 3A). However, a strong level of mPGES-1 signal was observed in the subluminal stroma immediately surrounding the implanting blastocyst, but not in the luminal and glandular epithelia at $0800 \mathrm{~h}$ on day 6 (Fig. 3B). No equivalent signals were seen in the inter-implantation areas on day 6 (Fig. 3C). In addition, after the mPGES-1 sense probe was used in place of the antisense probe, there were no detectable signals in the uterus on day 6 (Fig. 3D). At 2000 and $2400 \mathrm{~h}$ on day 6 , strong mPGES-1 signals were also observed in the subluminal stroma, similar to those at $0800 \mathrm{~h}$ on day 6 (Fig. 3E and F). On day 7, mPGES-1 signals were highly visible in the primary decidua (Fig. 3G). On days 8 and 9, mPGES-1 signals were strongly detected in the subluminal decidual cells at the mesometrial side (Fig. $3 \mathrm{H}$ ).

\section{mPGES-1 immunostaining during early pregnancy}

The pattern of mPGES-1 immunostaining during early pregnancy is similar to that of mPGES-1 mRNA signals and is shown in Fig. 4. There was no detectable signal on days $1-5$ (Fig. 4A). At $0800 \mathrm{~h}$ on day 6, mPGES-1 immunostaining was clearly observed in the subluminal stroma immediately surrounding the implanting blastocyst (Fig. $4 \mathrm{~B})$, whereas no signal was seen in the inter-implantation area (Fig. 4C). Compared with the morning, mPGES-1 immunostaining was detected in a slightly larger area of subluminal stroma at $2000 \mathrm{~h}$ on day 6 (Fig. 4D). After rabbit anti-human mPGES-1 antibody was preincubated with mPGES-1-blocking peptide, no signals were observed in the uterus (Fig. 4E). On day 7, mPGES-1 immunostaining was also highly visible in the subluminal decidual cells surrounding the embryo, but not on the mesometrial side (Fig. 4F). On day 8, mPGES-1 immunostaining was strongly detected in the primary decidua (Fig. 4G). On day 9, mPGES-1 immunostaining was strongly localized 

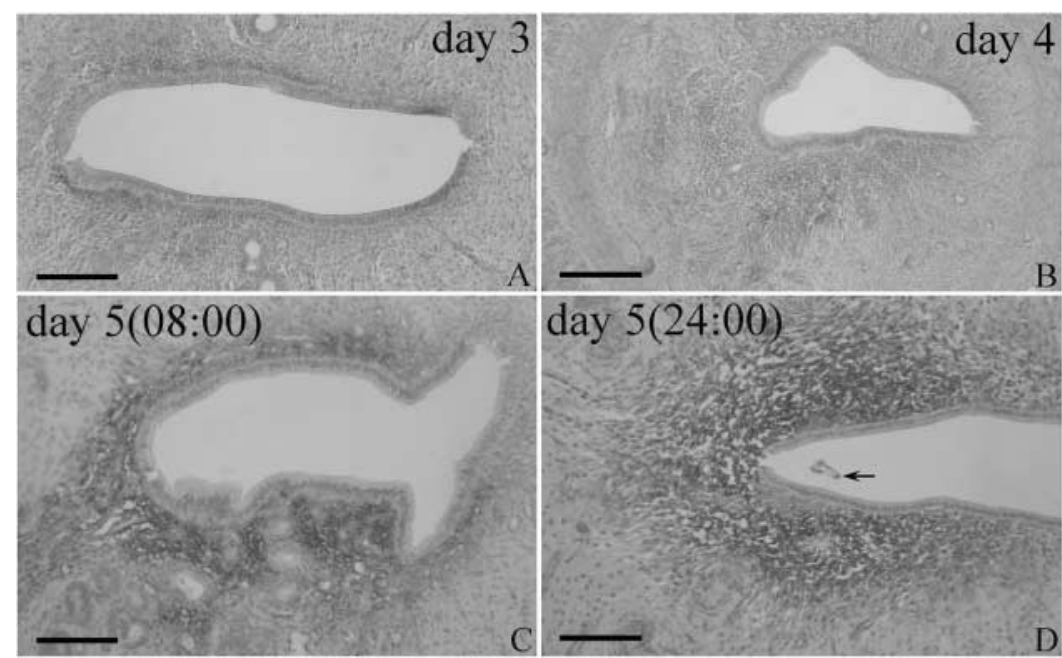
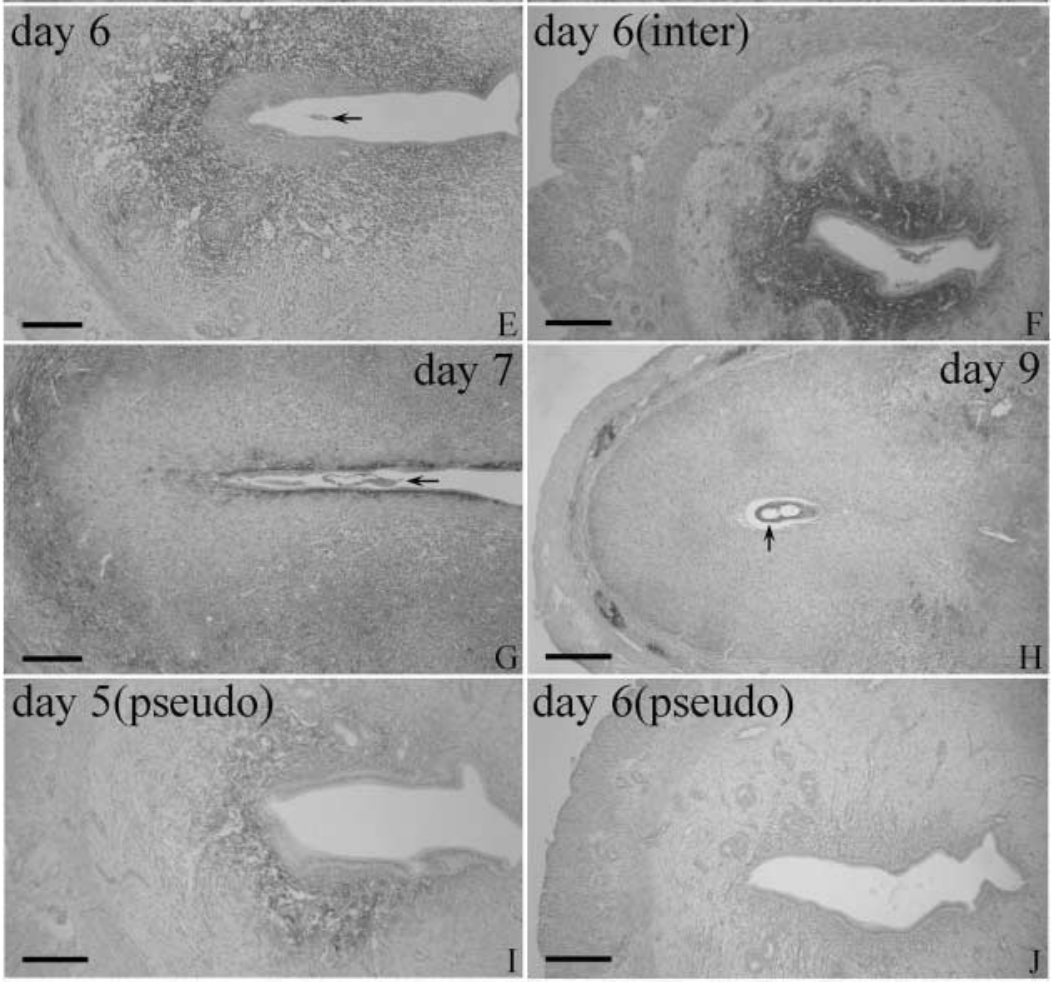

Figure 2 COX-2 immunostaining in rat uteri during early pregnancy on days $3(\mathrm{~A}), 4(\mathrm{~B}), 5(\mathrm{C}), 5$ (D, at $2400 \mathrm{~h}), 6$ (E, implantation site), 6 (F, inter-implantation site), $7(\mathrm{G})$ and $9(\mathrm{H})$. During pseudopregnancy, COX-2 immunostaining was seen in the subluminal stromal cells on day 5 (I), but not in rat uterus on day $6(\mathrm{~J})$. Arrows indicate embryos; scale bar, $60 \mu \mathrm{m}$. in the primary decidua and the decidual area on the mesometrial side (Fig. 4H).

\section{mPGES-1 expression during pseudopregnancy}

From days 1 to 6 of pseudopregnancy, there were no detectable signals for both mPGES-1 mRNA and immunostaining in the uterus (data not shown).

\section{mPGES-1 expression under delayed implantation and activation of implantation}

Under delayed implantation, there were no detectable signals for either mPGES-1 mRNA or immunostaining (Fig. 5A and $\mathrm{B})$. A low level of mPGES-1 mRNA and protein was detected in the subluminal stroma immediately surrounding the implanted blastocysts $24 \mathrm{~h}$ after delayed implantation was terminated by estrogen treatment (Fig. 5C and D). When delayed implantation was terminated by estrogen treatment for $36 \mathrm{~h}$, both mPGES-1 mRNA signals and immunostaining were strongly localized in the subluminal stroma immediately surrounding the implanted blastocysts (Fig. 5E and F), which were similar to the mPGES-1 expression on day 6 of pregnancy.

\section{Effects of nimesulide on MPGES-1 expression at the implantation site}

In order to examine the effects of nimesulide on mPGES-1 expression, pregnant rats on day 5 were treated once with 
mPGES-1 mRNA

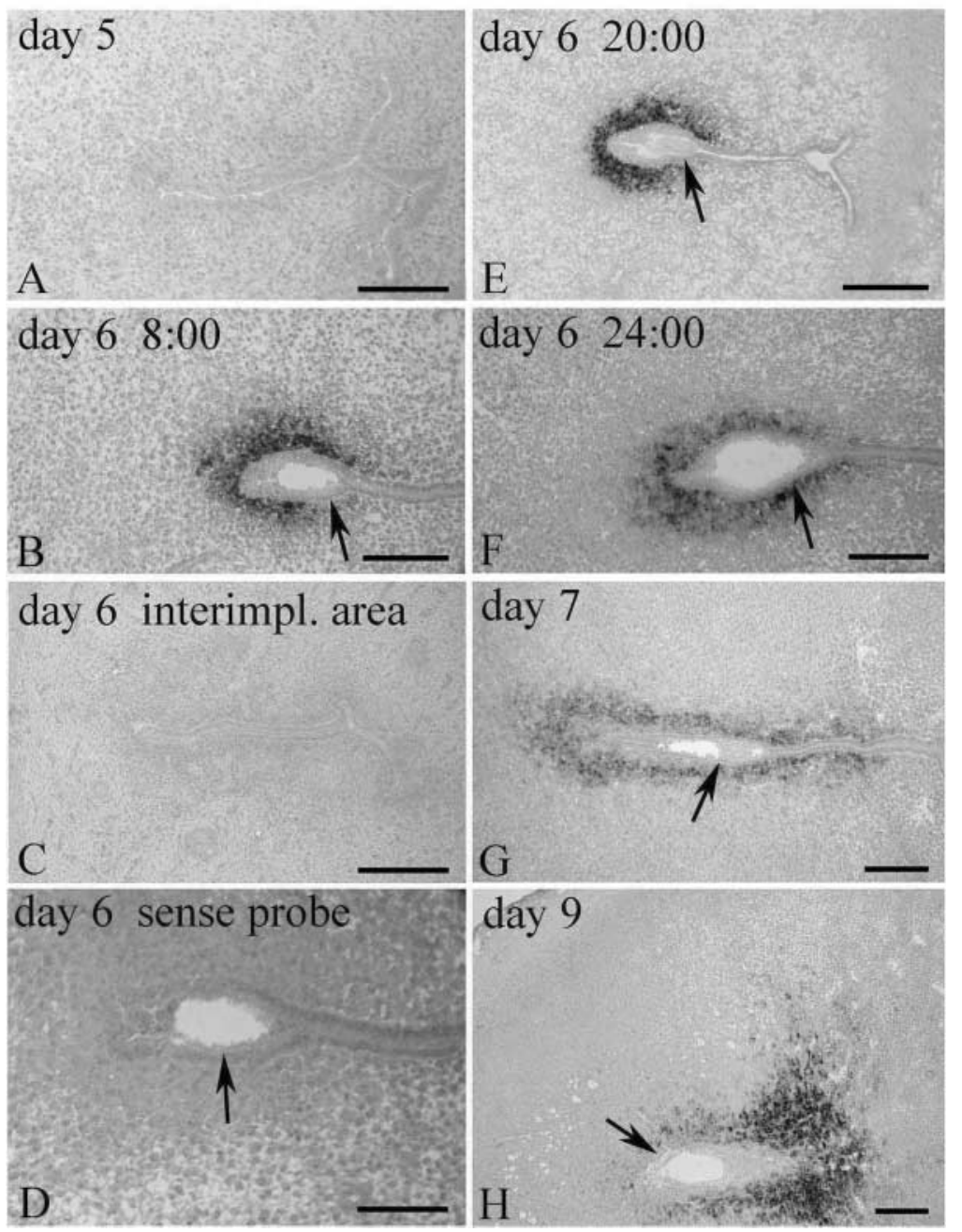

Figure 3 In situ hybridization of mPGES-1 mRNA in rat uteri during early pregnancy on days 5 (A), 6 (B, implantation site at $0800 \mathrm{~h}), 6(\mathrm{C}$, inter-implantation site), 6 (E, implantation site at $2000 \mathrm{~h}), 6$ (F, implantation site at $2400 \mathrm{~h}), 7(\mathrm{G})$ and $9(\mathrm{H})$. When the mPGES-1 sense probe was used in place of the antisense probe, there was no detectable signal in the uterus on day 6 of pregnancy (D). Arrows indicate embryos; scale bar, $60 \mu \mathrm{m}$. nimesulide for $24 \mathrm{~h}$ or treated twice on both days 5 and 6 for $48 \mathrm{~h}$. In the control, both mPGES-1 mRNA signals and immunostaining were strongly detected in the subluminal stroma immediately surrounding the implanted blastocysts like the mPGES-1 expression on day 6 (Fig. 6A and B). When pregnant rats were treated with nimesulide for $24 \mathrm{~h}$ on day 5, although there were no detectable changes in mPGES-1 mRNA signals (Fig. 6C), mPGES-1 immunostaining was significantly reduced to an undetected level (Fig. $6 \mathrm{D})$. In the control on day 7 , both mPGES-1 mRNA signals and immunostaining were highly visible in the subluminal primary decidual cells (Fig. 6E and F). After pregnant rats were treated with nimesulide for $48 \mathrm{~h}$, the signals for both mPGES-1 mRNA and immunostaining were significantly reduced to a low level (Fig. $6 \mathrm{G}$ and $\mathrm{H}$ ).

\section{cPGES immunostaining during early pregnancy}

There was no detectable cPGES immunostaining on days 1-5 of pregnancy (Fig. 7A and B). On day 6, cPGES immunostaining was highly visible in the luminal epithelium and subluminal stroma surrounding the implanted blastocyst (Fig. 7C), but was not seen in the inter-implantation site (Fig. 7D). On day 7, cPGES immunostaining was mainly seen in the primary decidua (Fig. 7E). On day 8, cPGES immunostaining was detected in the whole decidual cells (Fig. 7F).

\section{mPGES-2 immunostaining during early pregnancy}

There was a high level of mPGES-2 immunostaining in the luminal epithelium and a basal level in the glandular epithelium on day 1 (Fig. 8A). On days 2 and 3, mPGES-2 immunostaining was at an intermediate level in both luminal and glandular epithelia and at a low level in the subluminal stroma (Fig. 8B). On days 4 and 5 , a high level of mPGES-2 was seen in both luminal and glandular epithelia (Fig. 8C). Moreover, a similar pattern of mPGES-2 immunostaining was also seen on day 5 of pseudopregnancy (Fig. 8D). On day 6, mPGES- 


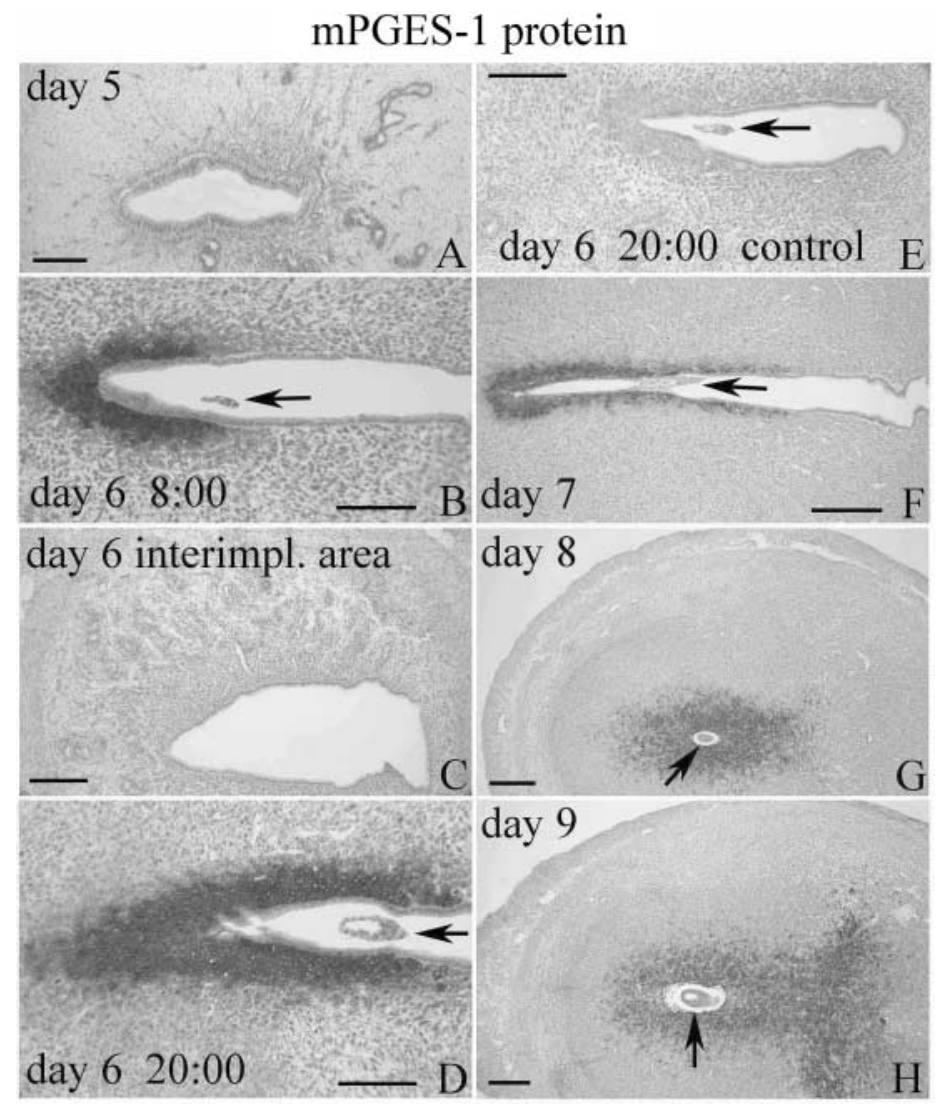

Figure 4 mPGES- 1 immunostaining in rat uteri during early pregnancy on days $5(\mathrm{~A}), 6$ (B, implantation site at $0800 \mathrm{~h}$ ), 6 (C, inter-implantation site), 6 (D, implantation site at $2000 \mathrm{~h}$ ), $7(\mathrm{~F}), 8(\mathrm{G})$ and $9(\mathrm{H})$. After rabbit anti-human mPGES-1 antibody was preincubated with mPGES-1 blocking peptide, there was no detectable immunostaining in rat uterus at $2000 \mathrm{~h}$ on day 6 of pregnancy (E). Arrows indicate embryos; scale bar, $60 \mu \mathrm{m}$.
2 immunostaining was at a high level in both luminal and glandular epithelia, and at a low level in the subluminal stroma at the implantation site (Fig. 8E), whereas mPGES-2 immunostaining was not seen in the inter-implantation site (Fig. 8F). However, there was only a low level of mPGES-2 immunostaining in both luminal and glandular epithelia on day 6 of pseudopregnancy (Fig. 8G). On days 7-9 of pregnancy, mPGES-2 immunostaining was highly visible in the decidual cells (Fig. 8H).

\section{PGIS immunostaining in the rat uterus during early pregnancy}

PGIS immunostaining was strongly detected in the myometrium on days $1-9$ of pregnancy (Fig. 9A, B and H). There was no detectable PGIS immunostaining in the luminal and glandular epithelia, and in the subluminal stroma, on days 1-5 of pregnancy (Fig. 9A and B). PGIS immunostaining was strongly detected in the luminal and glandular epithelia, and the stroma surrounding the implanting blastocyst, on day 6 of pregnancy (Fig. 9C), whereas there was a weak PGIS immunostaining only in the luminal epithelium and the subluminal stroma in the inter-implantation area (Fig. 9D). Similarly, a low level of PGIS immunostaining was seen in the luminal and glandular epithelia on day 6 of pseudopregnancy (Fig. 9E). On day 7 of pregnancy, PGIS immunostaining was also highly seen in the myometrium and primary decidua (Fig. 9F). After rabbit normal IgG was used to replace rabbit anti-PGIS antibody, no immunostaining was seen in the uterus on day 7 of pregnancy (Fig. 9G). PGIS immunostainng was strongly detected in the decidual cells on days 8 and 9 of pregnancy (Fig. 9H).

\section{Discussion}

In this study, both mPGES-1 mRNA and protein were highly visible in the subluminal stroma surrounding the implanting blastocyst at the implantation site on day 6, but were not seen in the inter-implantation site on day 6 of pregnancy or in the rat uterus on day 6 of pseudopregnancy. Moreover, both mPGES-1 mRNA and protein expression were detected after delayed implantation was terminated by estrogen treatments and embryos implanted. These results are consistent with those found in the mouse uterus ( $\mathrm{Ni}$ et al. 2002), but slightly different from results in the hamster (Wang et al. 2004b). In hamster uterus, mPGES-1 was highly expressed in both luminal epithelium and stromal cells around the implanting blastocyst on day 5, and mainly in primary decidual cells on day 6 (Wang et al. 2004b). However, mPGES-1 expression was not observed in the luminal epithelium in 


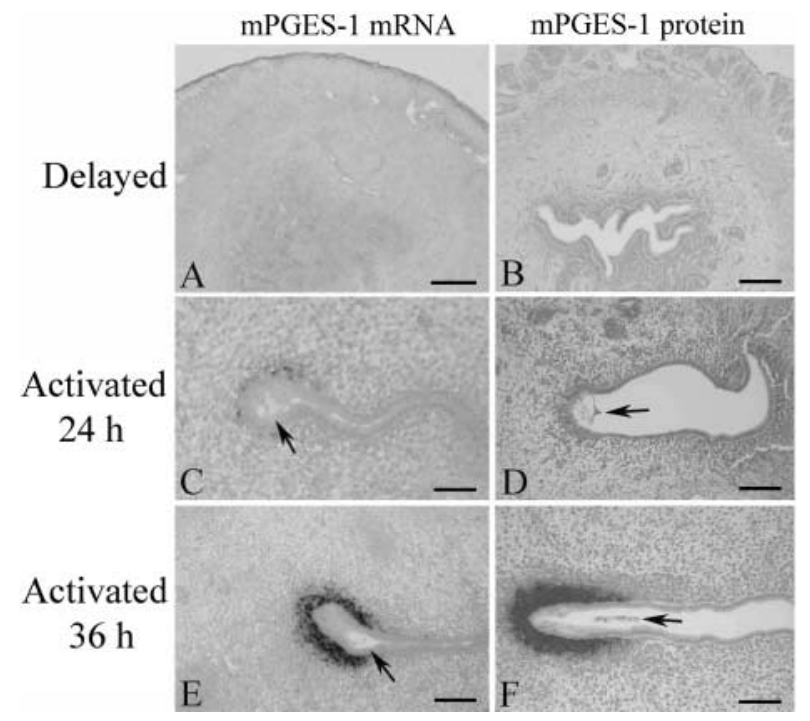

Figure 5 In situ hybridization of mPGES-1 mRNA and mPGES-1 immunostaining in rat uterus under delayed implantation and after activation with estrogen treatment. Arrows indicate implanting blastocysts; scale bar, $60 \mu \mathrm{m}$.

either rat or mouse uterus ( $\mathrm{Ni}$ et al. 2002). Our data suggest that mPGES-1 expression in rat uterus required the presence of an active blostocyst during the peri-implantation period.
Because mPGES-1 is preferentially coupled with the inducible COX-2 to promote delayed PGE2 generation (Murakami et al. 2000), we also examined COX-2 immunostaining in rat uterus. COX-2 immunostaining was strongly detected in the subluminal stromal cells on the morning of day 5, and also in the subluminal stromal cells surrounding the implanting blastocyst at midnight on day 5 of pregnancy. However, COX-2 immunostaining was seen in the secondary decidua but not in the primary decidua on the morning of day 6 . Although the COX-2 protein was not co-localized with mPGES-1 protein in the subluminal stromal cells at implantation sites, it is possible that the high level of COX-2 protein in this location may produce enough $\mathrm{PGH} 2$ for mPGES-1 to synthesize PGE2 in a slightly later stage.

Nevertheless, mPGES-1-deficient mice are viable and fertile, and develop normally compared with wild-type controls. mPGES-1-deficient mice displayed a marked reduction in inflammatory responses compared with mPGES-1 wild-type mice in multiple assays (Trebino et al. 2003). In another study, mPGES-1-deficient mice did not exhibit any detectable abnormality in the reproduction system either (Uematsu et al. 2002); in this system another PGES might compensate for mPGES-1 deficiency. In our study, cPGES and mPGES-2 were also strongly detected at the implantation site. During embryo implantation, it is possible that both CPGES and mPGES-2 might compensate

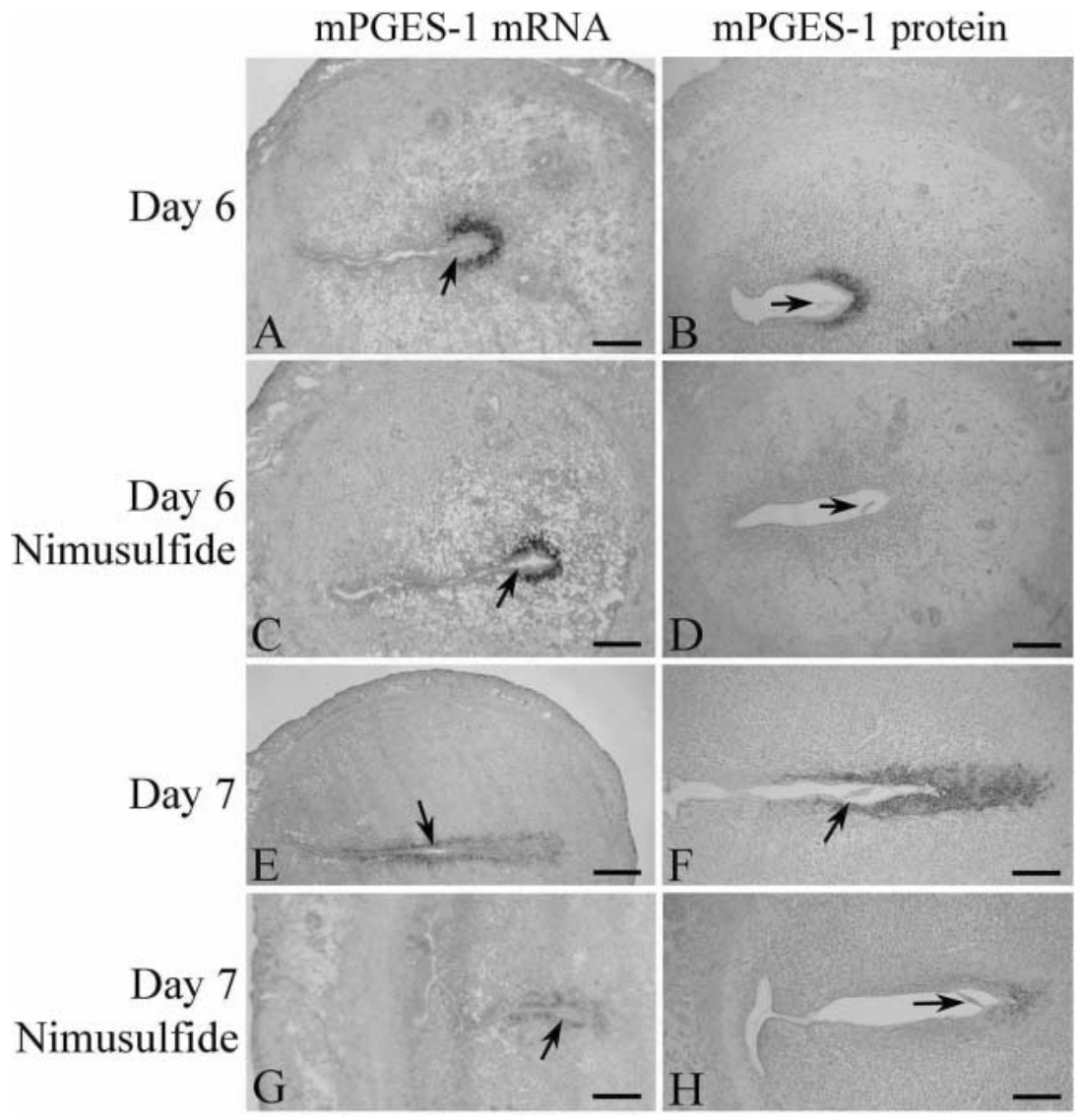

Reproduction (2006) 131 139-151
Figure 6 Effects of nimesulide on mPGES-1 expression in pregnant rat uterus. Pregnant rats were treated with nimesulide $(40 \mathrm{mg} / \mathrm{kg}$ in $0.2 \mathrm{ml}$ DMSO) on day 5 for $24 \mathrm{~h}$ or were treated twice on both days 5 and 6 for $48 \mathrm{~h}$. Arrows indicate implanting blastocysts; scale bar, $60 \mu \mathrm{m}$. 


\section{cPGES protein}
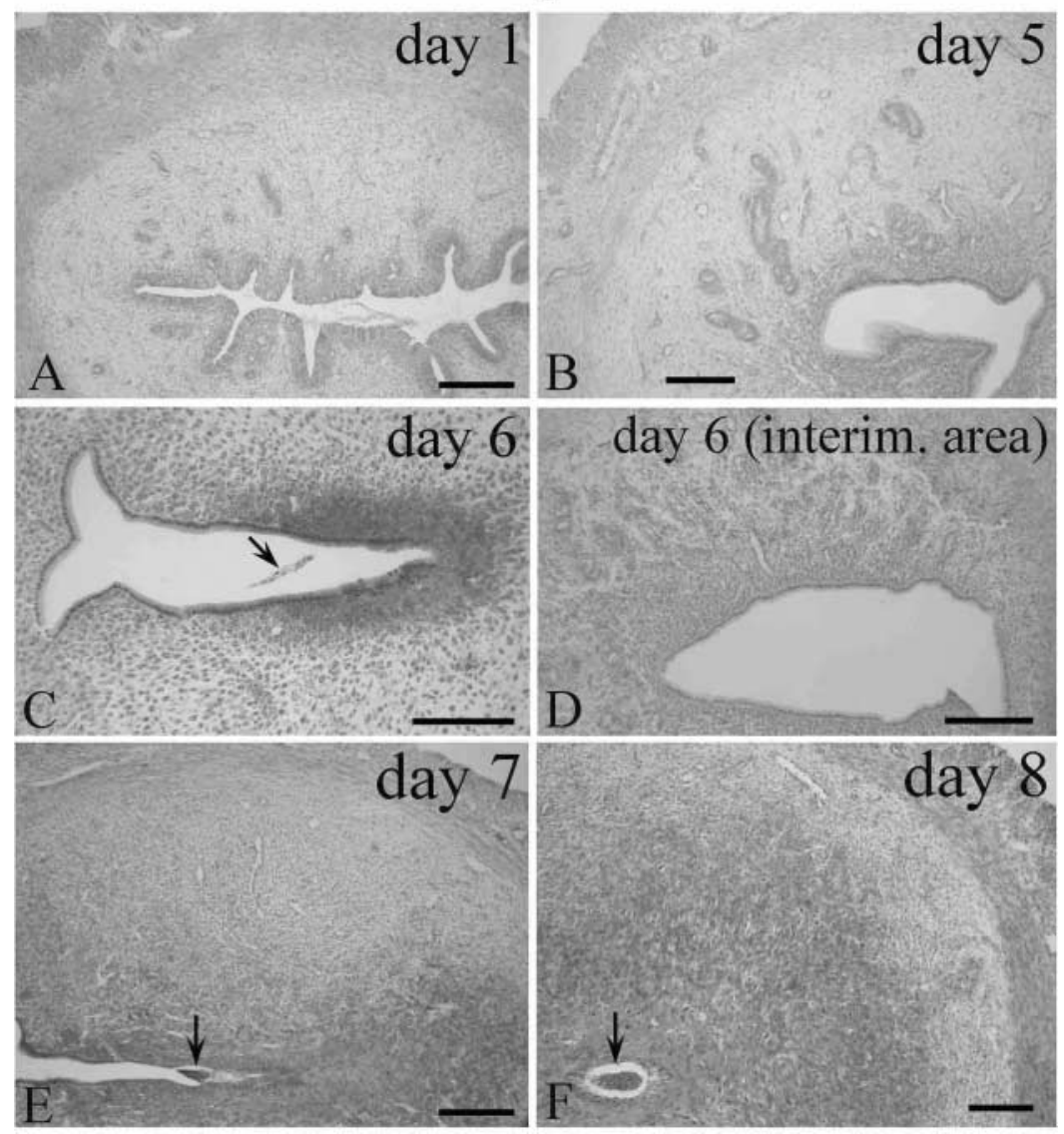

Figure 7 CPGES immunostaining in rat uteri on days 1 (A), 5 (B), 6 (C, implantation site), 6 (D, inter-implantation site), 7 (E) and $8(\mathrm{~F})$ respectively. Arrows indicate embryos; scale bar, $60 \mu \mathrm{m}$. for the mPGES-1 deficiency. In the mouse, COX-2 compensation occurs in the absence of COX-1 (Reese et al. 1999). Moreover, COX-1 can replace specific functions of COX-2 in vivo in the context of genetic disparity (Wang et al. 2004a). This kind of functional compensation among PGES isoforms has yet to be identified. A better approach is to see what kind of phenotypes could be obtained after all three PGES isoforms are deleted.

When pregnant rats were treated with nimesulide for $24 \mathrm{~h}$ on day 5, mPGES-1 protein expression was completely inhibited although implantation sites were still visible and mPGES-1 mRNA was still highly expressed in the subluminal stromal cells, compared with control. Additionally, both mPGES-1 mRNA and protein expression was significantly inhibited by 48 -h nimesulide treatment on day 5. Our results were consistent with previous studies with COX inhibitors. Several papers have shown that COX inhibitors had no significant effects on endometrial vascular permeability (Kennedy 1977, Phillips \& Poyser 1981, Sookvanichsilp \& Pulbutr 2002). However, COX-2 inhibitors could significantly reduce the uterine decidualization (Sookvanichsilp \& Pulbutr 2002). We also found that the size of the implantation sites and decidualization were severely affected by nimesulide, although nimesulide had no effect on the number of implantation sites (J. Cong et al., unpublished data). When infused into the lumen of sensitized rat uteri in which endogenous PG synthesis is inhibited, PGE2 is able to restore the endometrial vascular permeability response and decidualization (Kennedy \& Lukash 1982, Keys \& Kennedy 1990, Hamilton \& Kennedy 1994). In steroid-injected ovariectomized rats, following unilateral intrauterine instillation of sesame oil, administration of indomethacin inhibited the onset of the decidual cell reaction and had deleterious effects on the luminal epithelium. Inclusion of PGE2 in the instillate accelerated stromal cell differentiation and overcame the inhibitory effect of indomethacin (Keys \& Kennedy 1990). All of these data suggest that PGE2 is essential for rat decidualization. Mice devoid of COX-1 exhibit parturition defects (Langenbach et al. 1995). COX-2-depleted mice showed implantation and decidualization defects during early pregnancy (Dinchuk et al. 1995, Lim et al. 1997), suggesting the involvement of COX-2-directed PG synthesis in the process of implantation. Furthermore, COX-2 is aberrantly expressed in the uterus surrounding the blastocyst in leukemia inhibitory factor (LIF) $(-/-)$ mice (Song et al. 2000). LIF has been shown to be essential for mouse implantation (Stewart et al. 1992).

In the rat uterus, cPGES immunostaining was not seen on days 1-5 of pregnancy. However, cPGES immu- 


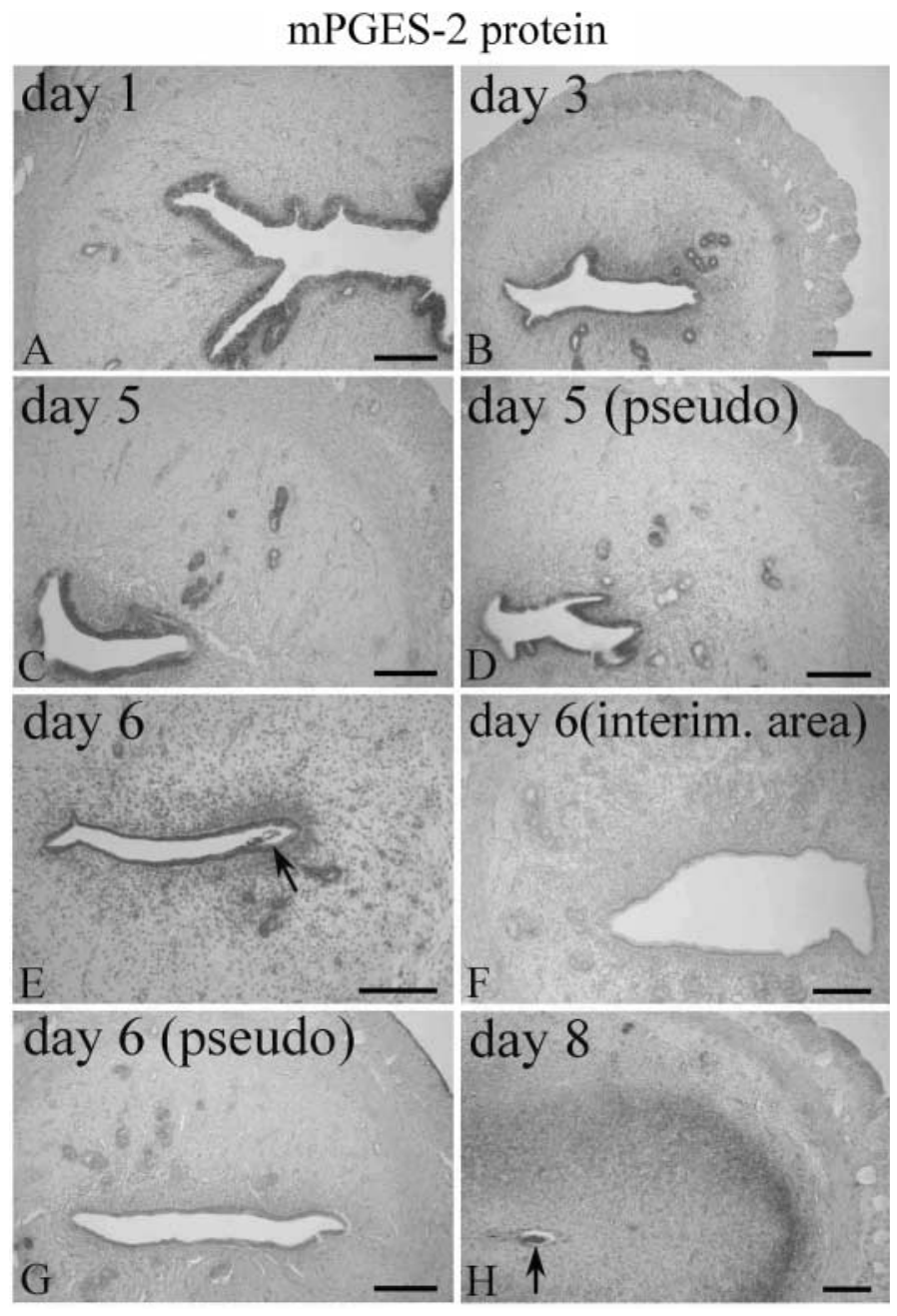

Figure 8 mPGES-2 immunostaining in rat uteri during early pregnancy on days 1 (A), 3 (B), 5 (C), 6 (E, implantation site), 6 (F, inter-implantation site) and $8(\mathrm{H})$. During pseudopregnancy, mPGES-2 immunostaining was shown on days 5 (D) and $6(\mathrm{G})$. Arrows indicate embryos; scale bar, $60 \mu \mathrm{m}$. nostaining was highly visible in the luminal epithelium and subluminal stromal cells immediately surrounding the implanting blastocyst on day 6 of pregnancy; this was slightly different from results in the mouse, where cPGES immunostaining was only detected in the luminal epithelium surrounding the implanting blastocyst, but not in the subluminal stroma at the implantation site on day 5 of pregnancy ( $\mathrm{Ni}$ et al. 2003). Because cPGES is constitutively expressed in a wide variety of cells and tissues, and is predominantly linked with COX-1 to promote an immediate response (Tanioka et al. 2000), COX-1 immunostaining in the rat uterus during early pregnancy was examined. Interestingly, COX-1 immunostaining was strongly detected in the luminal epithelium and weakly so in the subluminal stroma at the implantation site on day 6 of pregnancy. The co-localization of COX-1 and CPGES in the luminal epithelium at the implantation site may suggest a role for PGE2 production through this pathway. In human placenta, apoptotic early gestational syncytiotrophoblasts were heavily stained with CPGES, suggesting that CPGES could be involved in apoptosis or repair mechanisms (Meadows et al. 2004). It is well documented that the rodent uterine epithelium around the embryo undergoes apoptosis in response to the presence of the blastocyst (Schlafke et al. 1985, Parr et al. 1987, Welsh \& Enders 1991). cPGES may also be involved in apoptosis occurring at the implantation site.

mPGES-2 immunostaining was strongly detected in the luminal epithelium on days $1-5$ of pregnancy. On day 6 of pregnancy, mPGES-2 immunostaining was highly visible in the luminal epithelium and weakly seen in the subluminal stromal cells and glandular epithelium at the implantation site. In several cell lines, mPGES-2 promoted PGE2 production via both COX-1 and COX-2 in the immediate and delayed responses with modest COX-2 preference (Murakami et al. 2003). In this study, COX-1 and mPGES-2 were co-localized in the luminal epithelium at the implantation site, but mPGES-2 localization was very different from COX-2. It appears that mPGES-2 was mainly coupled with COX-1 to produce PGE2 in the luminal epithelium at the implantation site because mPGES-2 immunostaining was not observed in the inter-implantation site. 


\section{PGIS protein}
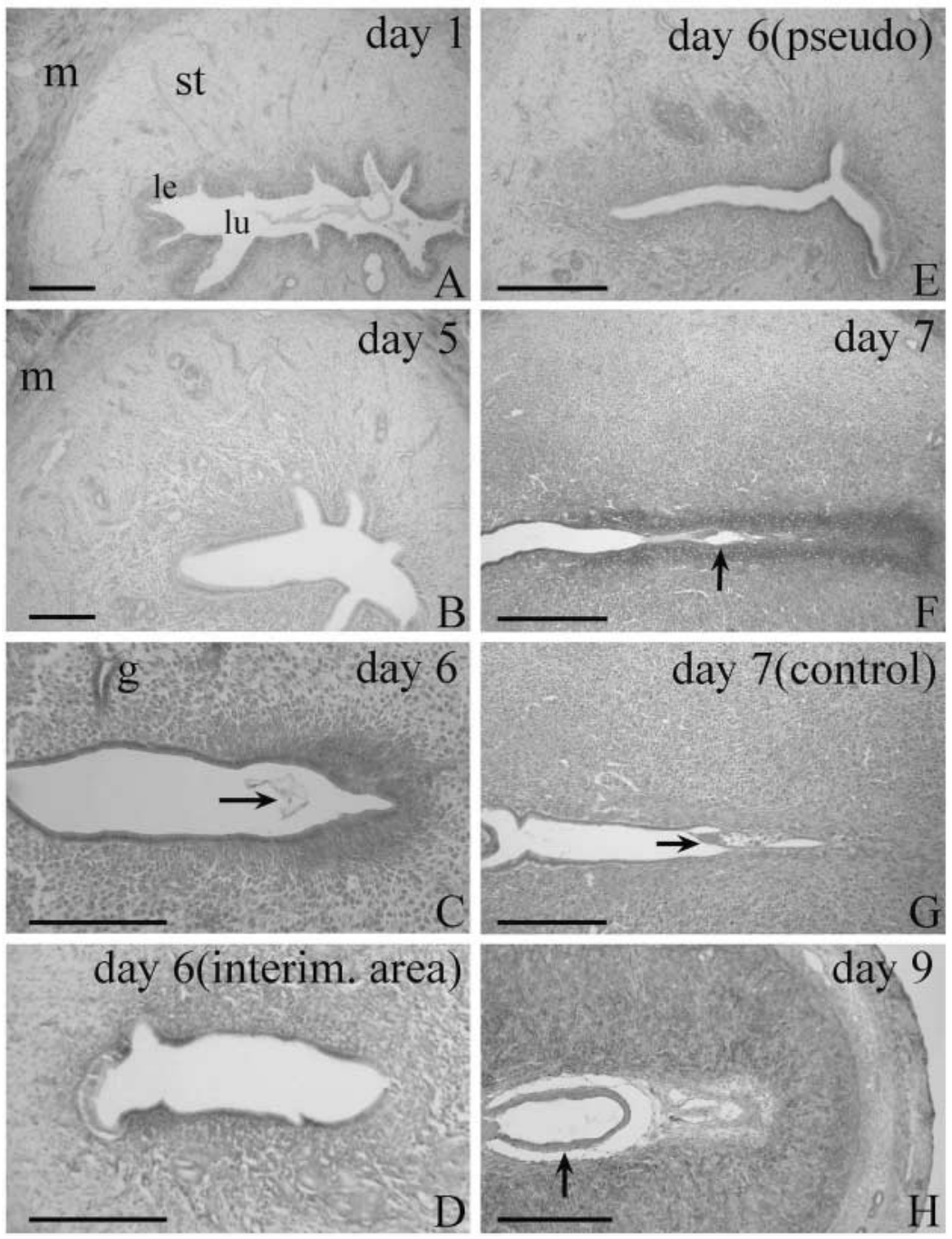

Figure 9 PGIS immunostaining in rat uteri on days 1 (A), 5 (B), 6 (C), 6 (D, inter-implantation area), $7(\mathrm{~F})$ and $9(\mathrm{H})$ of pregnancy. (E) PGIS immunostaining on day 6 of pseudopregnancy. After rabbit normal IgG was used to replace rabbit anti-PGIS antibody, no immunostaining was detected on day 7 of pregnancy $(\mathrm{G})$. Abbreviation: $\mathrm{m}$, myometrium. Scale bar, $60 \mu \mathrm{m}$. Arrows indicate embryos.
In our study, PGIS was also strongly detected at the implantation site in rat uterus although there was a high level of PGES expression. It was estimated that the concentration of 6-keto-PGF1 $\alpha$ (a stable metabolite of PGI2) in implantation sites on the evening of day 5 is at least 40-fold that in inter-implantation sites in rat uterus (Kennedy \& Zamecnik 1978). In mouse uterus, PGI2 is the most dominant prostaglandin followed by PGE2, and is significantly higher at implantation sites than at interimplantation sites (Lim et al. 1999). In contrast, Kennedy (1979) showed that, in the rat, PGE2 but not PGI2 is a key mediator of increased vascular permeability at the implantation site. In rat uterine homogenates during early pseudopregnancy and pregnancy, PGE2 peaked on day 5 of pseudopregnancy and on day 5 of pregnancy. Indomethacin treatment of rats during early pregnancy caused a delay in implantation, a significant reduction in uterine weight, and a much reduced number or absence of implanted blastocysts in the uterus on day 9
(Phillips \& Poyser 1981). In hamster, PGE2, but not PGI2, is the major PG at implantation sites where COX2 and mPGES-1 - but not PGI - synthases are coexpressed. This elevated uterine PGE2 at implantation sites may serve to initiate or amplify physiological signals required for specific aspects of the implantation process in hamsters (Wang et al. 2004b). In rhesus monkey uterus, the coupling of CPGES and COX-1 in the luminal epithelium may be responsible for the synthesis of PGE2 in monkey endometrium, and the coupling of mPGES and COX-2 in the glandular epithelium may be of importance for preparing the receptive endometrium (Sun et al. 2004).

In conclusion, at the implantation site in rat uterus, COX-1, cPGES and mPGES-2 were highly expressed in the luminal epithelium surrounding the implanting blastocyst, whereas COX-2 and mPGES-1 were highly visible in the subluminal stromal cells surrounding the implanting blastocyst, suggesting that PGE2 should be produced in 
large amounts through COX-2/mPGES- 1 , COX-1/CPGES and/or COX-1/mPGES-2 pathways. Because PGIS is also strongly expressed at the implantation site in rat uterus, it is possible that both PGE2 and PGI2 may be essential for rat implantation.

\section{Acknowledgements}

This work was supported by Chinese National Natural Science Foundation grants 30170110, 30570198, 30270163 and 30330060, and the Special Funds for Major State Basic Research Project (G1999055903). The authors declare that there is no conflict of interest that would prejudice the impartiality of this scientific work.

\section{References}

Baskar JF, Torchiana DF, Biggers JD, Corey EJ, Anderson NH \& Subramanian N 1981 Inhibition of hatching of mouse blastocysts in vitro by various prostaglandin antagonists. Journal of Reproduction and Fertility 63 359-363.

Chakraborty I, Das SK, Wang J \& Dey SK 1996 Developmental expression of the cyclo-oxygenase-2 genes in the peri-implantation mouse uterus and their differential regulation by the blastocyst and ovarian steroids. Journal of Molecular Endocrinology 16 107-122.

Dinchuk JE, Car BD, Focht RJ, Johnston JJ, Jaffee BD, Covington MB, Contel NR, Eng VM, Collins RJ, Czerniak PM, Gorry SA \& Trzaskos JM 1995 Renal abnormalities and an altered inflammatory response in mice lacking cyclooxygenase II. Nature $\mathbf{3 7 8}$ 406-409.

Hamilton GS \& Kennedy TG 1994 Uterine vascular changes after intrauterine infusion of indomethacin and prostaglandin E2 to rats sensitized for the decidual cell reaction. Biology of Reproduction $50757-764$.

Hla T \& Neilson K 1992 Human cyclooxygenase-2 cDNA. PNAS 89 7384-7388.

Holmes PV \& Gordashko BJ 1980 Evidence of prostaglandin involvement in blastocyst implantation. Journal of Embryology and Experimental Morphology 55 109-122.

Jakobsson PJ, Thoren S, Morgenstern R \& Samuelsson B 1999 Identification of human prostaglandin E synthase: a microsomal, gluthathione-dependent, inducible enzyme, constituting a potential novel drug target. PNAS 96 7220-7225.

Kennedy TG 1977 Evidence for a role of prostaglandins in the initiation of blastocyst implantation in the rat. Biology of Reproduction 16 286-291.

Kennedy TG 1979 Prostaglandins and increased endometrial vascular permeabiltiy resulting from the application of artificial stimulus to the uterus of the rat sensitized for the decidual cell reaction. Biology of Reproduction 20 560-566.

Kennedy TG \& Zamecnik J 1978 The concentration of 6-keto-prostaglandin F1alpha is markedly elevated at the site of blastocyst implantation in the rat. Prostaglandins 16 599-605.

Kennedy TG \& Lukash LA 1982 Induction of decidualization in rats by the intrauterine infusion of prostaglandins. Biology of Reproduction $27253-260$.

Keys JL \& Kennedy TG 1990 Effect of indomethacin and prostaglandin-E2 on structural differentiation of rat endometrium during artificially induced decidualization. American Journal of Anatomy 188 148-162.

Lala PK 1989 Similarities between immunoregulation in pregnancy and in malignancy: the role of prostaglandin E2. American Journal of Reproductive Immunology $20147-152$.

Langenbach R, Morham SG, Tiano HF, Loftin CD, Ghanayem BI, Chulada PC, Mahler JF, Lee CA, Goulding EH, Kluckman KD, Kim HS \& Smithies O 1995 Prostaglandin synthase I gene disrup- tion in mice reduces arachidonic acid-induced inflammation and indomethacin-induced gastric ulceration. Cell 83 483-492.

Lim H, Paria BC, Das SK, Dinchuk JE, Langenbach R, Trzaskos JM \& Dey SK 1997 Multiple female reproductive failures in cyclooxygenase 2-deficient mice. Cell 91 197-208.

Lim H, Gupta RA, Ma WG, Paria BC, Moller DE, Morrow JD, DuBois RN, Trzaskos JM \& Dey SK 1999 Cyclooxygenase-2-derived prostacyclin mediates embryo implantation in the mouse via PPARS. Genes and Development 13 1561-1574.

Meadows JW, Pitzer B, Brockman DE \& Myatt L 2004 Differential localization of prostaglandin E synthase isoforms in human placental cell types. Placenta 25 259-265.

Murakami M \& Kudo I 2004 Recent advances in molecular biology and physiology of the prostaglandin E2-biosynthetic pathway. Progress in Lipid Research 43 3-35.

Murakami M, Naraba H, Tanioka T, Semmyo N, Nakatani Y, Kojima F, Ikeda T, Fueki M, Ueno A, Oh-ishi S \& Kudo I 2000 Regulation of prostaglandin E2 biosynthesis by inducible membrane-associated prostaglandin E2 synthase that acts in concert with cyclooxygenase-2. Journal of Biological Chemistry 275 32783-32792.

Murakami M, Nakashima K, Kamei D, Masuda S, Ishikawa Y, Ishii T, Ohmiya Y, Watanabe K \& Kudo I 2003 Cellular prostaglandin E2 production by membrane-bound prostaglandin E synthase-2 via both cyclooxygenase-1 and -2. Journal of Biological Chemistry $27837937-37947$.

Negishi M, Sugimoto Y \& Ichikawa A 1995 Molecular mechanisms of diverse actions of prostanoid receptors. Biochimica et Biophysica Acta 1259 109-120.

Ni H, Sun T, Ding NZ, Ma XH \& Yang ZM 2002 Differential expression of microsomal PGE synthase at the implantation sites and in the decidual cells in mouse uterus. Biology of Reproduction $\mathbf{6 7}$ $351-358$.

Ni H, Sun T, Ma XH \& Yang ZM 2003 Expression and regulation of cytosolic prostaglandin E synthase in mouse uterus during the periimplantation period. Biology of Reproduction $\mathbf{6 8}$ 744-750.

Parr EL, Tung HN \& Parr MB 1987 Apoptosis as the mode of uterine epithelial cell death during embryo implantation in mice and rats. Biology of Reproduction 36 211-225.

Phillips CA \& Poyser NL 1981 Studies on the involvement of prostaglandins in implantation in the rat. Journal of Reproduction and Fertility 62 73-81.

Psychoyos A 1986 Uterine receptivity for implantation. Annals of the New York Academy of Sciences 476 36-42.

Reese J, Brown N, Paria BC, Morrow J \& Dey SK 1999 COX-2 compensation in the uterus of COX-1 deficient mice during the pre-implantation period. Molecular and Cellular Endocrinology $15023-31$.

Samet JM, Fasano MB, Fonteh AN \& Chilton FH 1995 Selective induction of prostaglandin $\mathrm{G} / \mathrm{H}$ synthase I by stem cell factor and dexamethasone in mast cells. Journal of Biological Chemistry $\mathbf{2 7 0}$ 8044-8049.

Schlafke S, Welsh AO \& Enders AC 1985 Penetration of the basal lamina of the uterine luminal epithelium during implantation in the rat. Anatomical Record 212 47-56.

Seibert K, Zhang Y, Leahy K, Hauser S, Masferrer J, Perkins W, Lee L \& Isakson P 1994 Pharmacological and biochemical demonstration of the role of cyclooxygenase 2 in inflammation and pain. PNAS 91 12013-12017.

Smith WL, Meade EA \& DeWitt DL 1994 Interactions of PGH synthase isozymes-1 and -2 with NSAIDs. Annals of the New York Academy of Sciences 744 50-57.

Smith WL, DeWitt DL \& Garavito RM 2000 Cyclooxygenases: structural, cellular, and molecular biology. Annual Review of Biochemistry 69 149-182.

Song H, Lim H, Das SK, Paria BC \& Dey SK 2000 Dysregulation of EGF family of growth factors and COX-2 in the uterus during the preattachment and attachment reactions of the blastocyst with the 
luminal epithelium correlates with implantation failure in LIF-deficient mice. Molecular Endocrinology 14 1147-1161.

Sookvanichsilp N \& Pulbutr P 2002 Anti-implantation effects of indomethacin and celecoxib in rats. Contraception $65373-378$.

Stewart CL, Raspar P, Brunet LJ, Bhatt H, Gadi I, Kontgen F \& Abbondanzo SJ 1992 Blastocyst implantation depends on maternal expression of leukemia inhibitory factor. Nature 359 76-79.

Sun T, Li SJ, Diao HL, Teng CB, Wang HB \& Yang ZM 2004 Cyclooxygenases and prostaglandin $\mathrm{E}$ synthases in the endometrium of the rhesus monkey during the menstrual cycle. Reproduction 127 $465-473$.

Tanioka T, Nakatani Y, Semmyo N, Murakami M \& Kudo I 2000 Molecular identification of cytosolic prostaglandin E2 synthase that is functionally coupled with cyclooxygenase- 1 in immediate prostaglandin E2 biosynthesis. Journal of Biological Chemistry 275 32775-32782.

Trebino CE, Stock JL, Gibbons CP, Naiman BM, Wachtmann TS, Umland JP, Pandher K, Lapointe JM, Saha S, Roach ML, Carter D, Thomas NA, Durtschi BA, McNeish JD, Hambor JE, Jakobsson PJ, Carty TJ, Perez JR \& Audoly LP 2003 Impaired inflammatory and pain responses in mice lacking an inducible prostaglandin E synthase. PNAS 100 9044-9049.

Uematsu S, Matsumoto M, Takeda K \& Akira S 2002 Lipopolysaccharide-dependent prostaglandin $\mathrm{E}(2)$ production is regulated by the glutathione-dependent prostaglandin $E(2)$ synthase gene induced by the Toll-like receptor 4/MyD88/NF-IL6 pathway. Journal of Immunology $1685811-5816$.

Wang H, Ma WG, Tejada L, Zhang H, Morrow JD, Das SK \& Dey SK 2004a Rescue of female infertility from the loss of cyclooxygenase2 by compensatory up-regulation of cyclooxygenase- 1 is a function of genetic makeup. Journal of Biogical Chemistry $\mathbf{2 7 9}$ 10649-10658.

Wang X, Su Y, Deb K, Raposo M, Morrow JD, Reese J \& Paria BC $2004 b$ Prostaglandin E2 is a product of induced prostaglandinendoperoxide synthase 2 and microsomal-type prostaglandin $\mathrm{E}$ synthase at the implantation site of the hamster. Journal of Biological Chemistry 279 30579-30587.

Welsh AO \& Enders AC 1991 Chorioallantoic placenta formation in the rat: I. Luminal epithelial cell death and extracellular matrix modifications in the mesometrial region of implantation chambers. American Journal of Anatomy 192 215-231.

Received 29 June 2005

First decision 2 August 2005

Revised manuscript received 21 September 2005

Accepted 26 September 2005 